\title{
Necessity of Offering Photographic Courses to Art and Design Majors
}

\author{
Huiying Wang \\ School of Art \& Design \\ Xi'an University of Technology \\ Xi'an, China
}

\begin{abstract}
In today's digital era, the continuous upgrading of digital technology has played a very good role in promoting the communication and exchange of pictures. Today's digital cameras are used almost at the same frequency as the computers and cellphones used in our daily lives. In many school of arts, photography is also offered to students majoring in arts and design. The photography courses have played a positive role in promoting the artistic creation of art majors. However, people who know about photography know that in order to take artistic pictures with a clear picture, reasonable composition, innovative ideas, and sense of aesthetic and form, we must first master a number of operating principles and shooting skills of professional SLR camera. This part of the training is not simply the copy of life, but the training through the photography skills and art forms. It can be said that the photographic art form can enhance one's accomplishments, aesthetic taste and the art reproduction of real life and it is also an enhancement of visual arts. Art is interlinked, so an art student who has self-cultivation, love the life and is good at observing life can also use photography to create profound artistic works if they are interested in photography.
\end{abstract}

Keywords—photography art; art form; artistic culture

\section{INTRODUCTION}

With the advent of information age, the characteristics of photographic art as a cultural phenomenon has become more and more distinct and has now become the information carrier of the interaction among social economy, human life and art and culture. Using pictures to communicate with each other has become the same linguistic form as all human. Therefore, the advent of the image age has provided opportunities and space for the prevalence of photographic education. As a result, many comprehensive universities also establish photography major and offer photography courses of artistic discipline. Many art students who like photography but do not choose the major for a variety of reasons have the opportunity to learn photography, learn to use cameras to express them and add color to their art learning path. Offering photographic elective courses for other art students largely enriches the creative vision of art students. Many art students reflect that learning photography knowledge also greatly promote and help their professional creation, and they can use the camera to directly create photography works that satisfy themselves. Therefore, it has been recognized and praised by students.
Many art design students buy cameras, because they often need to use the camera to shoot material for the creation of their own artistic works. However, they often can only use the automatic shooting function of the camera holding professional equipment, so the material usually cannot be used and they are not satisfied with the effect of their shooting. For example, some students raise such a question: why the picture I take is a virtual image? How can I highlight the subject I shoot in the picture? How can I shoot a charming night? The questions involve much most basic knowledge in photography. Therefore, it is said learning simple photography can easily solve many problems they meet in using the camera. Let's imagine that how can an unclear picture without prominence of subject and a stunning light and shadow effect add to your artistic design? Because they cannot use the function of camera, they cannot achieve the original artistic idea even with a good camera. Therefore, it is necessary for schools to offer photography basic elective courses for students majoring in design. Through the study of photography technology, they can have more ways and means to create a variety of advertising design works. Hence, studying photography and cultivating a strong interest in photography can rapidly improve the aesthetic ability of the individual; cultivating a unique view of photography can improve students' creative enthusiasm; cultivating good accomplishment of photography can enrich artistic creation space for art students. In our art college, photography has become a compulsory subject for art students as well as a practical form of artistic creation.

\section{TO CUltivate STRONG INTEREST IN PHOTOGRAPHY AND IMPROVE PERSONAL AESTHETIC ABILITY}

Photography is a comprehensive discipline that contains rich content. In photography teaching, students should first be encouraged to have the strong interest in learning, so teachers can show some outstanding photographic works in the classroom to attract students' visual sensibilities and let students to appreciate those good photographic works through detailed interpretation of the beauty of classic photography. They can interpret the inner and presentative image charm of the work from a professional perspective, and explain the shooting techniques, photography light, and composition, etc., so that students have some understanding of the moment art, photography and become interested in it. Therefore, it is said that training aesthetic ability is an 
effective and rapid guiding way. Second, during the teaching process, some typical events and anecdote about photography should be told to students to increase the active atmosphere in the classroom. In doing so, students can keep up with the teacher's rhythm and learning photography can become a happy thing. Therefore, listening is of great help to cultivating the interest of beginners. Thirdly, photography operation technique is the basis of photographic learning. It is impossible to talk about photography without considering techniques for photography. The teacher's purpose is to enable students to master the using principle of camera and shooting skills as soon as possible. It is indeed not difficult to learn the basic principles of how to operate the camera, since they are nothing more than the basic operating principles and parameters including the use of aperture and shutter speed, the method to control the exposure, as well as scope of depth of field. It can be said that they can be mastered as soon as students learn. However, we know that the ordinary meaning of being able to shoot pictures by holding a camera at the automatic gear is not equal to being able to shooting pictures by camera. People who did not learn photography can occasionally take a good picture, even if they totally do not understand use of the camera, which is generally because the environment itself is beautiful. However, after learning photography, they will learn to control their picture, operate their own picture, and take pictures by using photography method. The success rate of such photos must be greater than that of photos taken occasionally. Therefore, learning photography techniques includes the understanding of photographic equipment and photographic materials, photographic exposure, photographic light, the law of composition and systematic learning is the key. In short, the content of photography techniques is very rich, which needs to takes time to train, instead of empty talk, so it cannot be ignored. We all know the process of learning any one technology is a relatively boring thing. Hence, when teaching photography skills in the classroom, teachers should pay attention to transforming the theoretical knowledge point into operation practice. They should make a demonstration immediately every time they teach a technical difficulty, and require students to practice shooting in groups. They can enter the next part of the content until they understand the content and complete the direct operation. Photography course is a practical course, since theoretical knowledge should be tested in practice. This teaching method can enable students to directly understand each point that the teacher explains. Only in this way, can students quickly grasp the shooting skills in a relatively short period of time, so that they can shoot freely through diligent practice.

As a design major, studying photography is very necessary since photography is equivalent to the brush in our hands. The painting is done with a brush while photography is done with light. Art students can use the cameras instead of brushes in their hands in a wider creative space than that of photographic students to some extent. With the advent of digital age, camera equipment is more and more advanced and the degree of automation of digital cameras is also getting higher and higher. The photograph becomes more and more simple, and it seems that photography is less important. This is only for non-professionals, but automatic camera also needs to be controlled by human consciousness. In this process, the differences between the people who understand photography and those who are not good at photography in shooting a photo that shows the control over picture image in aspect of light, composition, field depth control is obvious. Art students can collect the creative materials they need for their art works through the study of photography techniques, and place the photographed highquality photographic materials into their design works through the computer PS processing, to provide more achievable means for their own works of art.

\section{To Cultivate A UNIQUE PHOTOGRAPHY VISION AND IMPROVE STUDENTS' CREATIVE ENTHUSIASM}

Although photographic image is the imaging that the camera produces by using optical principles through a series of chemical reactions or electronic sensitivities, there is an invisible bond connecting it with the photographers, showing the photographer's emotional appeal in his creation. During the process of deciding what to say to people in photos, capturing an instant picture, and selecting the picture effect, the photographer often adds his own standard to the artwork, and this is reproduction and performance of the reality made by the photographer in his own way. Due to the wide range of photographic arts, in photographic teaching, we have to make a design targeted for their photograph curriculum combining with the professional characteristics of students. In recent years, the author also teaches the basic photography course for visual communication majors in addition to the courses of photography majors. For non-photography students, my teaching plan is designed based on the special needs of their major. First of all, we know that visual communication majors have the same aesthetic orientation as photography majors, so the purpose of studying photography is to use photography to enrich the imperfection in their artistic creation or to enhance the artistic expressions with unique visual effects. If they learn to use the camera, they no longer rely solely on brushes to create their works of art, but they can use photography to create more and truer stereoscopic vision in two-dimensional space.

We often say that painting is addition, and photography is subtraction. Visual communication majors may be able to better understand this view. In the process of learning photography, they have to abandon the inherent add-on painting expression. When holding the camera in hand, they should be clear that they are doing photography now, and they should make targeted and selective shooting in the complex real world by using the knowledge learned in photography. Before shooting, we know that all the photos are instantly completed. In the face of this moment, the photographer can shoot from different angles with different composition and skills, so that people who see the photos have different interpretations. Occasional events will occur in most documentary photography, which are like adventures and photographers can experience it, witness it, and record it. How the photographer choose, arrange, construct, and manage in this process can show very personal art insights and self-cultivation. Different people shoot the same objective scene at the same time will produce varied results. 
Just like the oldest city wall in Xi'an, many people are shooting it, but the work is different. Although each photographer is presenting different wall that he sees in his eyes, but the good and bad of ultimate result is clear at a glance.

\section{TO CUlTIVATE GOOD PHOTOGRAPHY LITERACY TO ENRICH ART CREATION SPACE}

In the growing process of a person, good habits and interests and hobbies are important parts of life accumulation. Once they are engaged in their favorite career, they will quickly enter the role, and be immersed in it. Once you become a shutterbug, it will play a very important role in the future development. When a person with culture and life accumulation takes pictures by camera and looks at the landscapes and figures before his eyes, the image in front of him will show his own inner cultivation and cultural connotation reflected in the object he expresses. In particular, personal accomplishments and life accumulation have a great impact on his writing, which reflects the comprehensive quality of a person. It can be said that those who love photography or art creation have the personal accomplishments, cultural qualities, life experience and artistic appreciation at a certain height, which is the basis and source of a person's artistic creation.

A good photo is created by the author's in-depth understanding of the subject and rigorous conception. In other words, in order to take a good photo, in addition to being proficient in master the camera in hands and shooting skills, people must observe and accumulate in daily life to enrich their shooting experience. Only in this way can we make our photographic creation "come from life and be higher than life", so that the works we shoot can realize the perfect combination of the intent to be expressed and the social effect. Careful observation is the necessary prerequisite of photography creation. The so-called observation is the comprehensive grasp and understanding of all kinds of things and the connection between all things in the usual study and life. Through direct and extensive observation of the people and things in society and around us, they can constantly enrich their own direct and indirect experience, which are the basic condition and the necessary way to make photography creation. Only rich accumulation can help us shoot good photos. Long-term careful observation of life can continuously enrich our experience accumulation, finding the most typical things and the most essential things from the accumulated information and demonstrating by means of photography may create a good photo. In fact, there are many things that we experience firsthand or happen around us, but most of them did not attract our attention and did not arouse our enthusiasm for creation. It is because we usually do not observe carefully and have not formed a rich accumulation. Thus, we lose many opportunities for success. Many good, wonderful things passed by us without being discovered by us, and we may regret afterwards since we missed the shooting opportunity.

\section{CONCLUSION}

In short, as a popular art in the information age, photography is both a science and an art. It is necessary for students to learn photography knowledge. Nowadays, the society demands compound talents and among the comprehensive quality of students, art cultivation occupies an important position. Photography is not like the arts that have higher requirement for basic skills such as painting, sculpture, and dance, which need a long time training to achieve a certain artistic attainments. However, photography is not as easy as the people who do not understand see superficially. It is an instant art, so all the factors of photography you want to express should appear in your photo the moment you press the shutter. Only such picture can be called photographic works. The so-called various factor of photography is the fast response in the moment of repeated training and comprehensive quality of photographers. Art students can use photographic techniques to create the photography works with more image sense by combining with the unique visual language of the major. Judging from the photography works taken by students majoring in visual communication in these few years, reflection of their profession in photographic picture can be directly embodied. In addition to technology, the overall artistry of their photographic works is not worse than that of professional photography students, but there is a strong sense of composition, and more unique visual expression. This visual sense comes from their professional inclination. The author also intended to do so, hoping that they can give play to their own professional characteristics, and make good use of photographic means to express different visual sense of form.

\section{REFERENCES}

[1] Zhao Gui. Shadow of the sea boat. Xi 'an electronic science and technology university press., 2004.

[2] Liu Mingyuan. Photography Proceedings of Shaanxi University. Shaanxi university photography association, 2003. 